\title{
PERBEDAAN PENDAPATAN PETANI KARET YANG MEMASARKAN KE PASAR LELANG DAN LUAR PASAR LELANG DI DESA TELUK KUALI KECAMATAN TEBO ULU KABUPATEN TEBO
}

\author{
${ }^{1}$ Nida Kemala dan ${ }^{2}$ Yopi Gustian \\ ${ }^{1}$ Program Studi Agribisnis Fakultas Pertanian Universitas Batanghari Jambi \\ ${ }^{2}$ Alumni Program Studi Agribisnis Fakultas Pertanian Universitas Batanghari Jambi \\ Jl. Slamet Riyadi-Broni, Jambi. 36122. Telp. +62741 60103 \\ ${ }^{1}$ Email Korespondesi : nida_kemala@unbari.ac.id
}

\begin{abstract}
This research aimed to describe the rubber marketing activities to inside and outside ofauction market, to determine farmers income who sold rubber to the inside and outside ofauction marketand to know income differences between both the farmers who sold rubber to the inside and outside the auction market. This research was conducted in the Teluk Kuali Village there is a rubber inside as a reasan. There were 31 farmers as a sample. The results showed that there were a significant differences of income between farmers selling rubber products to the inside and outside of auction market, viewed as sig. $t$ (2-tailet) $=0,00<\alpha=0.05$. The income of the farmers who soldto the inside auction marketwas Rp. 1,336,407 $\mathrm{Ha}$ Month while the farmers who soldrubber to outside ofauction marketwas Rp. 952,962 Ha/Month.
\end{abstract}

Keywords: Difference, Income, Rubber, Auction

\begin{abstract}
Abstrak
Penelitian ini bertujuan untuk menggambarkan kegiatan pemasaran bokar ke pasar lelang dan luar pasar lelang dan mengetahui besarnya pendapatan petani yang menjual hasil bokar ke pasar lelang dan luar pasar lelang serta mengetahui perbedaan pendapatan petani yang menjual bokar ke pasar lelang dan luar pasar lelang. Penelitian dilaksanakan di Desa Teluk Kuali, Jumlah sampel penelitian sebanyak 31 RTP. Hasil penelitian menunjukan terdapat adanya perbedaan pendapatan antara petani yang menjual hasil bokar ke pasar lelang dan luar pasar lelang di Desa Teluk Kuali Kecematan Tebo Ulu Kabupaten Tebo, dilihat dari sig. $\mathrm{t}$ (2-tailet) $=0,00<\alpha=0,05$. Besar pendapatan petani yang menjualkan bokar ke pasar lelang Rp.1.336.407 Ha/Bln sedangkan petani yang menjualkan bokar ke luar pasar lelang sebesar Rp. $952.962 \mathrm{Ha} / \mathrm{Bln}$.
\end{abstract}

Kata Kunci: Perbedaan, Pendapatan, Karet, Lelang

\section{PENDAHULUAN}

Pembangunan pertanian di Indonesia memegang peranan penting dalam kegiatan pembangunan daerah, sehingga dalam pembangunannya selalu mendapat dukungan pemerintah. Sektor ini juga mampu memberikan lapangan pekerjaan serta sebagai pemasok bahan baku bagi sektor industri dan menjadi salah satu sumber devisa Negara (Kartasapoetra, 2008). Karet merupakan salah satu komoditas perkebunan dengan nilai ekonomis tinggi. Oleh karena itu, tidak salah 
jika banyak yang beranggapan bahwa tanaman karet adalah salah satu kekayaan Indonesia. Karet yang diperoleh dari proses penggumpalan getah tanaman karet (lateks) dapat diolah lebih lanjut untuk menghasilkan lembaran karet (sheet), bongkahan (kotak), atau karet remah (crumb rubber) yang merupakan bahan baku industri karet (Swarto, 2010).

Provinsi Jambi merupakan salah satu provinsi yang menghasilkan karet, salah satu kabupaten di Provinsi Jambi yang merupakan kabupaten penghasil karet adalah kabupaten Tebo dengan Produksi karet karet pada tahun 2017 sebesar 59.218 Ton, dan Produktivitas 0,52Ton/Ha dengan Luas Lahan 112.373 Ha.(BPS Provinsi Jambi, 2018). Kecamatan Tebo ulu merupakan salah satu Kecamatan di Kabupaten Tebo, yang sebagian besar penduduknya adalah petani karet, pada tahun 2017 Kecamatan Tebo Ulu mampu memproduksi karet sebesar 11.718 Ton/Ha dari Luas Lahan $15.610 \mathrm{Ha}$ dengan produktivitas 0,75 Ton/Ha (BPP Kabupaten Tebo, 2018).

Desa Teluk Kuali merupakan salah satu desa di Kecamatan Tebo Ulu yang memiliki produktivitas karet sebesar 1,05 Ton/Ha dengan jumlah produksi 1.626 Ton dengan luas lahan 1.542 Ha pada tahun 2017 (Data Kecamatan Tebo Ulu, 2018). Petani di desa ini menjual karet di dua tempat, pertama menjual ke pasar lelang dan kedua petani menjual ke luar pasar lelang. Dengan beroperasinya pasar lelang, tidak berarti hilang peranan luar pasar lelang (toke) di daerah operasinya, peran mereka justru lebih diperlukan untuk berperan aktif sebagai pembeli, tujuan pembentukan pasar lelang adalah untuk meningkatkan pendapatan dan kesejahteraan petani. Walaupun sudah ada pasar lelang, petani karet di desa Teluk Kuali masih banyak yang menjual hasil bokar ke luar pasar lelang (toke) dikarenakan pasar lelang hanya beroperasi 2 minggu sekali sedangkan petani ratarata menghasilkan bokar 1 minggu 1 kali. Oleh sebab itu maka peneliti tertarik mengambil judul "Perbedaan pendapatan petani karet yang memasarkan ke pasar lelang dan luar pasar lelang"

\section{METODOLOGI PENELITIAN}

Penelitian ini dilaksanakan di Desa Teluk Kuali, Kecamatan Tebo Ulu, Kabupaten Tebo. Pemilihan lokasi peneliti ini dipilih secara sengaja (purposive) dengan pertimbangan bahwa di Desa Teluk Kuali terdapat pasar lelang karet. Lingkup penelitian ini difokuskan pada gambaran kegiatan pemasaran bokar oleh petani, berapa besarnya pendapatan petani karet, serta perbedaan pendapatan petani karet. Penelitian ini dilaksanakan pada bulan Januari 2019. Jenis data berdasarkan skala ukur data rasio. Skala rasio memiliki nilai yang mutlak dan datanya dapat dikalikan atau dibagi. Sedangkan data berdasarkan waktu adalah data cross section(pada satu waktu tertentu).

Winarno (1994), mengemukakan bahwa untuk pedoman umum saja dapat dikatakan bahwa bila populasi cukup homogen terhadap populasi dibawah 100 RTP dapat dipergunakan sampel sebesar 50\% dan apabila populasi diatas 100 RTP sebesar $15 \%$ dan juga untuk sampel manusia, sampel hendaknya diatas 30 orang besarnya. Berdasarkan pertimbangan uraian diatas maka diambil sampel sebanyak 31 RTP dari populasi petani 118 RTP, secara snowball sampling (bola salju). Alasan penggunaan teknik snowball sampling, karna dari 118 RTP tidak 
ada data resmi yang menunjukan petani yang menjual karet ke dua pasar, yaitu pasar lelang dan luar pasar lelang. Teknik snowball sampling, sampel yang semula berjumlah kecil kemudian anggota sampel (responden) mengajak para sahabatnya atau menunjukan orang yang lain yang menurutnya memiliki informasi yang dibutuhkan untuk dijadikan sampel dan seterusnya sehingga jumlah sampel semakin banyak jumlahnya seperti bola salju yang sedang mengelinding semakin jauh semakin besar (Ali M, 2013). Alat analisis yang dilakukan dalam penelitian ini adalah berupa alat analisis deskriptif (kualitatif dan kuantitatif). Untuk menjawab tujuan pertama digunakan analisis deskriptif merupakan analisis yang dilakukan secara deskriptif yaitu dirumuskan dan mengumpulkan dengan cara menginterprestasikan, sehingga memberikan keterangan gambaran yang ada, dan analisis kuantitatif yaitu analisis yang berupa angka atau bilangan (Azwar, 1998). Untuk menghitung total biaya menggunakan rumus menurut Soekartawi (1995) sebagai berikut:

$\mathrm{TC}=\mathrm{TFC}+\mathrm{TVC}$

Dimana :

$\mathrm{TC} \quad=$ Total Biaya atau Total Cost $(\mathrm{Rp} / \mathrm{Ha} / \mathrm{bln})$

$\mathrm{TFC}=$ Total Biaya atauTetap Total Fix $\operatorname{Cost}(\mathrm{Rp} / \mathrm{Ha} / \mathrm{Bln})$

$\mathrm{TVC}=$ Total Biaya Tidak Tetapatau Total Variabel Cost $(\mathrm{Rp} / \mathrm{Ha} / \mathrm{bln})$

Selanjutnya untuk menghitung besarnya penerimaan dihitung dengan menggunakan rumus menurut Soekartawi (1995) sebagai berikut:

TR $=$ Y.Py

Dimana :

$\mathrm{TR}=$ Total penerimaan atau Total Revenue $(\mathrm{Rp} / \mathrm{Ha} / \mathrm{bln})$

$\mathrm{Y} \quad=$ Hasil produksi atau Product $(\mathrm{Kg} / \mathrm{Ha} / \mathrm{bln})$

Py = Harga produk atau Price Product $(\mathrm{Rp} / \mathrm{kg})$

Selanjutnya untuk menghitung besarnya pendapatan dapat di hitung dengan menggunakan rumus menurut Soekartawi (1995) sebagai berikut :

$\pi=\mathrm{TR}-\mathrm{TC}$

Dimana :

$\pi \quad=$ Pendapatan usaha tani atau Income $(\mathrm{Rp} / \mathrm{Ha} / \mathrm{bln})$

$\mathrm{TR}=$ Total penerimaan atau Total Revenue $(\mathrm{Rp} / \mathrm{Ha} / \mathrm{bln})$

$\mathrm{TC}=$ Total pengeluaran atau Total $\operatorname{Cost}(\mathrm{Rp} / \mathrm{Ha} / \mathrm{bln})$

Untuk menghitug biaya tetap, digunakan rumus menurut Sudarman dan Algifari (2001) sebagai berikut :

$\mathrm{BPA}=\frac{D-S}{N}$

Dimana :

$\mathrm{BPA}=$ Biaya penyusutan alat $(\mathrm{Rp} / \mathrm{Ha} / \mathrm{bln})$

$\mathrm{D}=$ Nilai Awal Alat $(\mathrm{Rp} / \mathrm{Ha})$

$\mathrm{S} \quad=$ Nilai Sisa $(\mathrm{Rp} / \mathrm{Ha})$

$\mathrm{N}=$ Umur Ekonomis (bln) 
Asumsi $\mathrm{S}=0$

Perbedaan pendapatan petani uji $\mathrm{t}$ - dua sampel berpasangan (Sampel paired test) dengan rumus (sudradjat $\mathrm{M}, 2000$ ) sebagai berikut :

$t_{\text {hit }}=\frac{\bar{d}}{s_{d / \sqrt{n}}}$ pada db $=\mathrm{n}-1 \mathrm{dan} S_{d}=\sqrt{\frac{\sum d_{i}^{2} \frac{\left(\sum d_{i}\right)^{2}}{n}}{(n-1)}}$

Dimana :

$\bar{d}=$ Rata-rata selisih pendapatan usahatani karet yang menjual ke pasar lelang dan luar pasar lelang $(\mathrm{Rp} / \mathrm{Ha} / \mathrm{bln})$

$s_{d}=$ Standar deviasi selisih pendapatan petani yang menjual ke pasar lelang dan luar pasar lelang

$\mathrm{d}=$ Selisih pendapatan petani yang menjual ke pasar lelang dan luar pasar lelang $(\mathrm{Rp} / \mathrm{Ha} / \mathrm{bln})$

$\mathrm{n}=$ Jumlah sampel petani

Hipotesis Operasional :

$\mathrm{H}_{0}$ : Tidak terdapat perbedaan pendapatan antara petani yang menjual hasil bokar ke pasar lelang dan luar pasar lelang.

$\mathrm{H}_{1}$ : Terdapat perbedaan pedndapatan antara petani yang menjual hasil bokar ke pasar lelang dan luar pasar lelang.

Hipotesis Stasistik :

$\mathrm{H}_{0}: \mathrm{d}=0$

$\mathrm{H}_{1}: \mathrm{d} \neq 0$

Kaidah keputusan :

Tolak $\mathrm{H}_{0}$ jika $\left|t_{\text {hit }}\right|>\left(t_{\alpha} / 2 ; \mathrm{n}-1\right)$

Terima $\mathrm{H}_{0}$ jika $\left|t_{\text {hit }}\right| \leq\left(t_{\propto} / 2 ; \mathrm{n}-1\right)$

\section{A. Identitas Petani Umur Petani}

Tabel 1 menunjukkan bahwa petani yang mempunyai frekuensi paling banyak berada dalam kelompok 27-30 Tahun yaitu sebanyak 11 RTP dengan persentase 35,48\% dan frekuensi petani paling sedikit adalah kelompok umur 4346 tahun dengan jumlah RTP 2 dengan persentase 6,45\%. Hal ini menunjukan bahwa semua petani sampel berada dalam kategori umur produktif, umur petani terkait adanya inovasi, seseorang pada umur non produktif akan cenderung sulit menerima inovasi, sebaliknya seseorang dengan umur produktif akan lebih mudah dan cepat menerima inovasi. Hal ini sesuai dengan pendapat Soekartawi (2005) bahwa makin muda petani biasanya mempunyai semangat untuk ingin tahu apa yang belum mereka ketahui, sehingga mereka berusaha untuk lebih cepat melakukan adopsi inovasi walaupun biasanya mereka masih belum berpengalaman dalam mengadopsi inovasi tersebut. 
Tabel 1. Distribusi Frekuensi Petani Berdasarkan Kelompok Umur Di Desa Teluk Kuali, Tahun 2019

\begin{tabular}{cccc}
\hline No & $\begin{array}{c}\text { Distribusi kelompok umur } \\
\text { (tahun) }\end{array}$ & $\begin{array}{c}\text { Frekuensi } \\
(\text { RTP })\end{array}$ & $\begin{array}{c}\text { Persentase } \\
(\%)\end{array}$ \\
\hline 1 & $27-30$ & 11 & 35,48 \\
2 & $31-34$ & 4 & 13 \\
2 & $35-38$ & 6 & 19,35 \\
4 & $39-42$ & 5 & 16,12 \\
5 & $43-46$ & 2 & 6,45 \\
6 & $47-50$ & 3 & 9,6 \\
\hline \multicolumn{2}{c}{ Sumber : Data Primer yang diolah, Tahun 2019 } & \multicolumn{2}{c}{100} \\
\end{tabular}

\section{Pendidikan Petani}

Saridewi (2010), menyatakan bahwa tingkat pendidikan seseorang dapat mengubah pola pikir, daya penalaran yang lebih baik, sehingga makin lama seseorang mengenyam pendidikan akan makin rasional. Distribusi frekuensi petani berdasarkan tingkat pendidikan formal dapat dilihat pada Tabel 2 berikut ini:

Tabel 2. Distribusi Frekuensi Petani Berdasarkan Tingkat Pendidikan Formal Di Desa Teluk Kuali, Tahun 2019

\begin{tabular}{cccc}
\hline No & $\begin{array}{c}\text { Distribusi Tingkat } \\
\text { Pendidikan }\end{array}$ & $\begin{array}{c}\text { Frekuensi } \\
(\text { RTP })\end{array}$ & $\begin{array}{c}\text { Persentase } \\
(\%)\end{array}$ \\
\hline 1 & SD & 17 & 54,8 \\
2 & SMP & 9 & 29,1 \\
3 & SMA & 5 & 16,1 \\
\hline & Jumlah & 31 & 100 \\
\hline
\end{tabular}

Sumber : Data Primer yang diolah, tahun 2019

Dari Tabel 2 diatas terlihat bahwa jumlah terbanyak berdasarkan tingkat pendidikan formal yang pernah diselesaikan petani sampel adalah SD yaitu sebanyak 17 RTP $(54,8 \%)$. Sedangkan petani yang paling sedikit adalah SMA dengan jumlah 5 RTP $(16,1 \%)$. Dari tabel diatas dapat ditarik kesimpulan bahwa mayoritas petani menamatkan pendidikan SD.

\section{Pengalaman Berusahatani}

Tabel 3 menunjukkan bahwa petani yang paling banyak adalah yang telah berusahtani 6-8 tahun dengan jumlah RTP 10 (32,25\%). Sedangkan yang terkecil adalah yang telah berusahatani 18-20 tahun dengan jumlah RTP $2(6,4 \%)$.

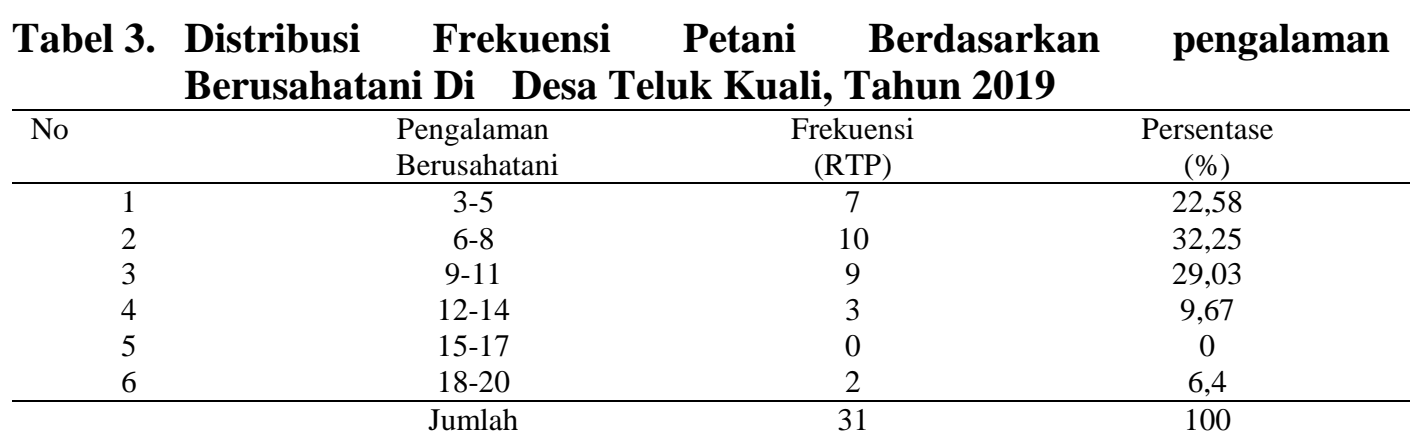

Sumber : Data Primer yang diolah, Tahun 2019 


\section{Jumlah Tanggungan Keluarga}

Hernanto (1996), jumlah tanggungan keluarga petani berpengaruh terhadap kegiatan ekonomi pada usahtaninya.Tanggungan keluarga merupakan salah satu faktor yang mempengaruhi keberhasilan berusahatani, semakin banyak jumlah tanggungan keluarga maka semakin banyak kebutuhan yang akan dipenuhi oleh petani. Tanggungan keluarga terdiri dari istri, anak serta anggota keluarga lainnya yang tinggal bersama dalam keluarga sekaligus menjadi tanggung jawab kepala keluarga. Untuk lebih jelasnya jumlah tanggungan keluarga petani dapat dilihat padaTabel 4.

Tabel 4. Distribusi Frekuensi Petani Berdasarkan Tanggungan Keluarga Di Desa Teluk Kuali, Tahun 2019

\begin{tabular}{cccc}
\hline No & $\begin{array}{c}\text { Tanggungan Keluarga } \\
(\text { Orang) }\end{array}$ & $\begin{array}{c}\text { Frekuensi } \\
(\text { RTP })\end{array}$ & $\begin{array}{c}\text { Persentase } \\
(\%)\end{array}$ \\
\hline 1 & 1 & 4 & 13 \\
2 & 2 & 18 & 58 \\
3 & 3 & 7 & 22,5 \\
4 & 4 & 2 & 6,5 \\
\hline & Jumlah & 31 & 100 \\
\hline
\end{tabular}

Sumber : Data Primer yang diolah, Tahun 2019

Tabel 4 diatas diketahui bahwa tanggungan keluarga petani yang terbesar adalah 2 orang yaitu 18 RTP, dan Petani yang memiliki tanggungan keluarga paling sedikit adalah 4 orang yaitu 2 RTP. Besarnya jumlah anggota keluarga disatu sisi dapat memacu petani lebih giat bekerja untuk menghasilkan produksi karet yang tinggi guna untuk memenuhi kebutuhan keluarganya (Soeharjo dan Patong, 1973)

\section{Luas Lahan Petani}

Tanah adalah pabrik hasil pertanian, tempat proses produksi berjalan selanjutnya menghasilkan produk pertanian (Mubyarto,1986).

Tabel 5. Distribusi Frekuensi Petani Berdasarkan Luas Lahan Di Desa Teluk Kuali Tahun 2019

\begin{tabular}{cccc}
\hline No & $\begin{array}{c}\text { Luas Lahan } \\
(\mathrm{Ha})\end{array}$ & $\begin{array}{c}\text { Frekuensi } \\
(\mathrm{RTP})\end{array}$ & $\begin{array}{c}\text { Persentase } \\
(\%)\end{array}$ \\
\hline 1 & $1,0-1,3$ & 9 & 29 \\
2 & $1,4-1,7$ & 4 & 13 \\
3 & $1,8-2,1$ & 9 & 29 \\
4 & $2,2-2,5$ & 3 & 9 \\
5 & $2,6-2,9$ & 0 & 0 \\
6 & $3,0-3,3$ & 6 & 20 \\
\hline
\end{tabular}

Sumber : Data Primer yang diolah, Tahun 2019

Dari Tabel 5 diatas menunjukan bahwa petani yang paling banyak yaitu petani sampel yang memiliki luas lahan antara 1,0-1,3 dan 1,8-2,1 ha luas lahan 
dengan jumlah 9 RTP dengan persentase 29\%. Sedangkan petani yang meiliki luas lahan terrendah yaitu 2,2-2,5 dengan jumlah RTP 3 dengan persentase 9\%.

\section{Biaya Tetap Dan Biaya Variabel}

Biaya tetap (fixed cost) yang dihitung pada penelitian ini biaya yang dikeluarkan berdasarkan biaya penyusutan alat-alat yang termasuk biaya tetap dalam penelitian ini adalah pisau sadap,parang, cangkul, batu asah, ember, mangkok karet. untuk melihat jumlah rata-rata biaya tetap untuk petani yang menjual bokarnya ke pasar lelang dan luar pasar lelang dapat dilihat pada Tabel 6.

Biaya variabel(variable cost) yang dihitung penelitian ini adalah biaya yang berubah-ubah sesuai dengan perubahan output, yang termasuk biaya variabel adalah cuka getah, tawas, jasa transportasi, dan timbangan basi.

Tabel 6. Rata-Rata Total Biaya Berdasarkan Jenis Peralatan Produksi Karet Di Desa Teluk Kuali, Tahun 2019.

\begin{tabular}{|c|c|c|c|c|}
\hline \multirow[b]{2}{*}{ No } & \multicolumn{2}{|c|}{ Uraian Komponen Biaya } & \multicolumn{2}{|c|}{ Jumlah (Rp/Ha/Bln) } \\
\hline & $\begin{array}{l}\text { Jenis peralatan dan } \\
\text { input }\end{array}$ & $\begin{array}{l}\text { Petani Yang Menjual } \\
\text { Ke Pasar Lelang } \\
\text { (Rp/Ha/Bln) }\end{array}$ & $\begin{array}{l}\text { Petani Yang Menjual } \\
\text { Luar Pasar Lelang } \\
\text { (Rp/Ha/Bln) }\end{array}$ & $\begin{array}{l}\text { Biaya } \\
\text { Tetap } \\
\text { Total }\end{array}$ \\
\hline \multirow[t]{7}{*}{1} & Biaya Tetap & 18.043 & 18.043 & 36.086 \\
\hline & 1. Pisau sadap & 1.315 & 1.315 & 2.630 \\
\hline & 2. Parang & 457 & 457 & 914 \\
\hline & 3. Cangkul & 446,5 & 446,5 & 893 \\
\hline & 4. Batu asah & 1.000 & 1.000 & 2.000 \\
\hline & 5. Ember & $1.124,5$ & $1.124,5$ & 2.249 \\
\hline & 6. Mangkok karet & 13.664 & .53 .664 & 27.328 \\
\hline \multirow[t]{6}{*}{2} & Biaya Variabel & 57.232 & 170.017 & 227.249 \\
\hline & 1. Cuka getah & 3.824 & 3.824 & 7.648 \\
\hline & 2. Tawas & $2.730,5$ & $2.730,5$ & 5.461 \\
\hline & 3. Jasa tranportasi & 22.061 & 0 & 44.122 \\
\hline & 4.Timbangan basi & 0 & $78.453,5$ & 156.907 \\
\hline & Jumlah total biaya & 75.275 & 188.060 & \\
\hline
\end{tabular}

Sumber : Data Primer yang diolah, Tahun 2019

Dari Tabel 6di atas terlihat rata rata biaya tetap memiliki rata-rata yang sama sedangkan rata-rata biaya variabel yang dikeluarkan berbeda, dikarenakan adanya perbedaan antara biaya jasa tranportasi dan timbangan basi yang di keluarkan petani. Petani yang menjual bokarnya ke pasar lelang menggeluakan biaya jasa tranportasi sebesar Rp.44.122 /Ha/Bln sedangkan petani yang menjual bokar luar pasar lelang mengeluarkan biaya timbangan basi sebesar Rp.156.907 $/ \mathrm{Ha} / \mathrm{Bln}$. 


\section{Penerimaan}

Tabel 7. Rata-Rata Produksi Yang Terjual, Harga, Dan Penerimaan Di Desa Teluk Kuali, Tahun 2019

\begin{tabular}{cccc}
\hline No & Keterangan & Ke Pasar Lelang & Luar Pasar Lelang \\
\hline 1 & Produksi yang terjual & 394,83 & 344,21 \\
2 & Harga & 7000 & 6500 \\
\hline & Penerimaan & 1.411 .673 & 1.141 .023 \\
\hline
\end{tabular}

Sumber : Data Primer Yang Diolah, Tahun 2019

Dari Tabel 7di atas rata-rata produksi yang terjual ke pasar lelang adalah sebesar 394,83 Kg/Ha sedangkan rata-rata produksi luar pasar lelang sebelum adanya timbangan basi adalah sebesar $392,09 \mathrm{Kg} / \mathrm{Ha}$, setelah potongan timbangan basi rata-rata produksi luar pasar lelang yang terjual adalah sebesar 344,21 Kg/Ha.

Rata-rata penerimaan petani yang menjual bokar ke pasar lelang adalah sebesar Rp.1.411.673/Ha/Bln, sedangkan rata-rata penerimaan petani yang menjualkan bokar luar pasar lelang adalah sebesar Rp.1.141.023/Ha/Bln. Ratarata penerimaan petani yang menjualkan bokar ke pasar lelang lebih besar dbandingkan petani yang menjualkan bokar luar pasar lelang.

\section{Pendapatan}

Pendapatan karet di Desa Teluk Kuali adalah selisih antara penerimaan dengan total biaya produksi. Penerimaan adalah jumlah produksi di kali dengan harga bokar petani. Total biya produksi adalah penjumlahan dari biaya cuka getah, tawas, jasa tranportasi, timbangan basi dan alat-alat (pisau sadap, parang, cangkul, batu asah, ember, mangkok karet) dapat dilihat Tabel 8. Tabel tersebutmenjelaskan bahwa rata-rata penerimaan petani daerah penelitian untuk petani yang menjual bokarnya ke pasar lelang adalah sebesar Rp.1.411.683 /Ha/Bln dan untuk petani yang menjual bokarnya luar pasar lelang adalah sebesar Rp.1.141.023 /Ha/Bln. Rata-rata total biaya untuk petani yang menjual bokarnya ke pasar lelang adalah sebesar Rp.75.275/Ha/Bln dan untuk petani yang menjual bokarnya luar pasar lelang adalah sebesar Rp.188.060 /Ha/Bln. Rata-rata pendapatan petani yang menjual bokarnya ke pasar lelang adalah sebesar Rp.1.336.407/Ha/Bln dan untuk petani untuk petani yang menjual bokarnya luar pasar lelang adalah sebesarRp.952.962/Ha/Bln. Rata-rata pendapatan petani yang menjual bokarnya ke pasar lelang lebih besar dari pada petani yang menjual bokarnya luar pasar lelang. Selisih rata-rata pendapatan petani yang menjual bokarnya ke pasar lelang dan luar pasar lelang adalah sebesar Rp.383.445 $/ \mathrm{Ha} / \mathrm{Bln}$. 
Tabel 8. Rata-Rata Penerimaan, Total Biaya Produksi Dan Pendapatan Petani Karet Di Desa Teluk Kuali, Tahun 2019

\begin{tabular}{llcc}
\hline No & Keterangan & $\begin{array}{c}\text { Petani Yang Menjual } \\
\text { Ke Pasar Lelang } \\
(\mathrm{Rp} / \mathrm{Ha} / \mathrm{Bln}\end{array}$ & $\begin{array}{c}\text { Petani Yang Menjual } \\
\text { Luar Pasar Lelang } \\
(\mathrm{Rp} / \mathrm{Ha} / \mathrm{Bln})\end{array}$ \\
\hline 1 & Penerimaan & 1.411 .683 & 1.141 .023 \\
2 & Total biaya & 75.275 & 188.060 \\
& produksi & 1.336 .407 & 952.962 \\
\hline
\end{tabular}

Sumber :Data Primer yang diolah, Tahun 2019

Pendapatan petani yang menjualkan bokar ke pasar lelang dan luar pasar lelang adalah sebesar Rp.2.289.369/Ha/bln, pendapatan petani dengan rata rata luas lahan 1.91 Ha adalah sebesar Rp.5.526.947/Bln dibandingkan dengan UMR jambi Rp.2.423.888 pendapatan petani ternyata lebih besar.

\section{Perbedaan Pendapatan Pada Pasar Lelang Dan Luar Pasar Lelang Dengan Luar Pasar Lelang}

Dari analisis uji t dua rata-rata sampel berpasangan yang dilakukan antara pendapatan petani yang menjual bokarnya ke pasar lelang dengan petani yang menjual bokarnya luar pasar lelang dapat di lihat pada Tabel 9.

\begin{tabular}{cccc}
\hline Sampel & Pendapatan & t-hitung & t-tabel \\
\hline Ke Pasar Lelang & $1.336,407$ & & \\
Luar Pasar & 952,962 & 7.791 & 2,052 \\
Lelang & & & \\
\hline
\end{tabular}

Sumber : Data Primer yang diolah, Tahun 2019

Dari Tabel 9 di atas melalui Uji Stasistik ( Uji T ) maka di peroleh t-hitung 17.791 lebih besar dari pada t-tabel 2,042 dengan $\alpha=0,05$. Sama hal dengan menggunakan SPSS dimana hasil t-hitung 17.791 sig. (2-tailet) $=000<\alpha=0,05$.

Dari penjelasan di atas maka Ho ditolak, hal ini berarti bahwa terdapat perbedaan pendapatan antara petani yang menjualkan bokar ke pasar lelang dengan luar pasar lelang..

\section{KESIMPULAN}

1. Produksi karet di daerah penelitian dimana rata-rata produksi petani yang menjualkan bokar ke pasar lelang adalah $394,83 \mathrm{Kg} / \mathrm{Ha} / \mathrm{Bln}$. Sedangkan ratarata produksi petani yang menjualkan bokar ke luar pasar lelang adalah 344,21 $\mathrm{Kg} / \mathrm{Ha} / \mathrm{Bln}$. Bentuk bokar yang di jual petani berbentuk slab tebal.

2. Rata-rata pendapatan petani yang menjual ke pasar lelang adalah sebanyak Rp.1.336.407 /Ha/Bln sedangkan petani yang menjual luar pasar lelang adalah sebanyak RP. $952.962 / \mathrm{Ha} / \mathrm{Bln}$. Jadi selisih antara petani yang menjual bokar ke pasar lelang dan luar pasar lelang adalah sebanyak RP. $383.445 / \mathrm{Ha} / \mathrm{Bln}$.

3. Terdapat perbedaan pendapatan antara petani yang menjual karet ke pasar lelang dengan luar pasar lelang. 


\section{DAFTAR PUSTAKA}

Ali M. (2013). Stasistik Untuk Penelitian Pendidikan.Nuha Medika.Yogyakarata Azwar. 1998. Metodologi Penelitian Edisi 3. STIE YKPN. Yogyakarta.

BPP Kabupaten Tebo. 2018. Tebo Dalam Angka Tebo. Jambi

BPS Provinsi Jambi. 2018.Provinsi Jambi Dalam Angka. BPS. Jambi.

Hernanto, F.1996. Ilmu Usahatani. Penebar Swadaya. Jakarta

Kartasapoetra, 2008. Manajemen Pertanian. Bina Aksa. Jakarta

Mubyarto. 1986. Pengantar Ekonomi Pertanian LP3ES. Jakarta

Saridewi (2010). Mengembangkan Pendidikan Berkarakter Melalui Implementasi High-Tech And High-Touch. Dalam Procceding Seminar Aktualisasi Pendidikan Krakter Bangsa, Universitas Pendidikan Indonesia

Soeharja A Dan D Patong. Patong. Patong. 1973. Sendi - Sendi Pokok Ilmu Usahatani. Departemen Ilmu Social Ekonomi Fakultas Pertanian IPB. Bogor

Soekartawi Dkk. 1995. J.I. Dilon Dan H.P Hardaker. 1995. Ilmu Usahatani Dan Penelitian Untuk Pengembangan Petani Kecil. Ui Press Jakarta

Swarto, 2010. Budidaya Tanaman Unggulan Perkebunan. Jakarta. Penebar Swadaya.

Winarno S. 1994. Pengantar penelitian ilmiah (dalam metode teknik). Penerbit kansius Bandung. 